\title{
A CRISE AÉREA NA MÍDIA BRASILEIRA: SIGNIFICADOS E ARTICULAÇÕES
}

\author{
LA CRISIS AÉREA EN LOS MEDIOS BRASILEÑOS: SIGNIFICADOS Y \\ ARTICULACIONES
}

\section{THE AIR CRISIS IN BRAZILIAN MEDIA: MEANINGS AND ARTICULATIONS}

\author{
Jouberte Maria Leandro Santos \\ Professora IFPE \\ joubertemaria@gmail.com \\ Sérgio Carvalho Benício de Mello \\ Professor UFPE \\ sergio.benicio@gmail.com \\ Carlos Everaldo Silva da Costa \\ Professor UFAL \\ carloseveraldo@gmail.com
}

\section{Resumo}

O presente artigo buscou explorar o discurso da crise aérea sob a ótica dos meios de comunicação e assim compreender como essas mídias significam a crise. A abordagem desse trabalho se desenvolveu na perspectiva da Teoria do Discurso de Laclau e Moufee (1987). Foi percebido que, de maneira geral, as mídias privadas são divididas no que diz respeito a considerar, ou o Governo ou as empresas aéreas - com foco na GOL e na TAM - como culpadas. Há uma cadeia de equivalência no discurso da revista Veja e do portal G1 em culpar o Governo por essa crise, enquanto que o Estadão culpa as empresas. Todavia, os blogs tiveram posturas antagônicas às mídias privadas em busca de defender os controladores, considerados por esses blogs como injustiçados. A coleta de dados se deu pelos documentos em trinta e três sites e dez blogs, com reportagens de 2006 a 2013.

Palavras-Chave: Crise Aérea; Teoria do Discurso; Mídia.

\begin{abstract}
This paper sought to explore the discourse of air crisis from the perspective of the media and thus understand how these media mean the crisis. The approach of this work is developed from the perspective of Discourse Theory of Laclau and Moufee (1987). It was noticed that, in general, the private media are divided with regard to consider or the government or the airlines - with a focus on GOL and TAM - as guilty. There is a chain of equivalence in the speech of Veja magazine and portal G1 to blame the government for the crisis, while the Estadão blame companies. Nonetheless, blogs had antagonistic postures to private media seeking to defend the drivers, voted for these blogs as wronged. The taping took the documents to thirty-three sites and ten blogs, with reports from 2006 to 2013.
\end{abstract}

Keywords: Air Crisis; Discourse Theory; media 


\section{Resumen}

El presente artículo buscó explorar el discurso de la crisis aérea bajo la óptica de los medios de comunicación y así comprender como esos medios significan la crisis. El enfoque de ese trabajo se desarrolló en la perspectiva de la Teoría del Discurso de Laclau y Moufee (1987). Fue percibido que, de forma general, los medios de comunicación privados están divididos en cuanto que consideran, al Gobierno o a las compañías aéreas - con un enfoque en GOL y TAM - como culpables. Hay una cadena de equivalencias en el discurso de la revista Veja y en el portal G1 a la hora de culpar al Gobierno por esa crisis, mientras que el Estado culpa a las empresas. Además, los blogs tuvieron posturas antagónicas en los medios privados buscando la defensa de los controladores, considerados por esos blogs como injustamente tratados. El análisis de datos de los reportajes, recopilación que fue dada por los documentos en treinta y tres sitios web y diez blogs, con los informes de 2006 a 2013.

Palabras clave: Crisis aérea, Teoría del Discurso, Medios de Comunicación.

\section{INTRODUÇÃO}

A aviação se transformou em um modal de mobilidade urbana, por ser um meio de transporte econômico, prático, rápido e seguro. Porém, o Brasil enfrenta uma crise neste setor, com atrasos, acidentes, greves e corrupção. Dentre os fatores iniciais da crise, destaca-se o acidente em 2006 que envolveu o choque, em pleno espaço aéreo, de um Boeing da GOL com um jato Legacy da empresa Excel Aire, que resultou em 154 mortes. Outro acontecimento, em outubro do mesmo ano, foi a pane nos radares do Cindacta 2 (Curitiba) que atrasou 145 voos. Em novembro, os controladores de voo - militares do baixo escalão hierárquico - iniciaram um protesto que atrasou decolagens e pousos. Na sequência, em dezembro, foram registrados os maiores atrasos nos aeroportos brasileiros, com filas, confusões e revolta dos passageiros.

Em 2007 o aeroporto de Congonhas fechou suas pistas devido o acúmulo de água da chuva e provocou atrasos pelo país, já que esse aeroporto representa um hubby do setor. Em março desse ano, os controladores fizeram a maior rebelião desde 1963, época em que houve acidente do Convair PP-CDW "Sirius", da empresa Cruzeiro do Sul, que - ao decolar - fez um pouso de emergência por conta de problemas de comunicação com os controladores e isso fez o avião cair sobre uma residência próxima ao aeroporto de Congonhas. Nesse acidente, um dos tripulantes era o deputado responsável por presidir uma Comissão Parlamentar de Inquérito - CPI, com função de investigar as causas do grande número de acidentes aéreos ocorridos no país naquela época. A criação dessa comissão seria motivada pelo acidente com outro Convair 340 durante o Voo 435 da Real Transportes Aéreos, no qual a esposa desse mesmo deputado também perdera a vida, o que fechou aeroportos e atrasou voos.

Já em julho de 2007, funcionários dos aeroportos Tom Jobim (RJ), Cumbica (SP) e Manaus (AM), anunciaram greve antes dos jogos Pan-Americanos. Nesse mês, um avião da 
TAM derrapou na pista de Congonhas, atravessou uma avenida e chocou-se com um prédio que continha combustível e gerou uma explosão em que morreram 190 pessoas.

Diante desta crise, diversos setores da sociedade brasileira se manifestaram. Dentre as discussões, a mídia brasileira assume papel de destaque, por representar os veículos aos quais a população se informa e constrói opinião. Assim, o discurso da mídia passou a ser importante pela sua capacidade de constituir discursos. Para o trabalho, houve o interesse em tentar entender tal discurso através da Teoria do Discurso (TD), cuja origem foi na obra de Laclau e Mouffe, denominada Hegemony and socialist strategy, de 1985. Explicitamente, essa é uma teoria pós-marxista e pós-estruturalista, de tradição crítica, conforme Lima (2011). Laclau (2000) diz que a TD é uma desconstrução da teoria marxista, ou seja, sócio-construtivista.

Os discursos são construídos social e politicamente, e estabelecem um sistema de relações entre objetos e práticas, o que possibilita o desenvolvimento de posições de sujeito nas quais os agentes sociais podem se identificar. A dinâmica inerente em um campo social gera uma disputa constante em torno das definições de sociedade e de identidade. Basicamente, na TD, todas as ações e objetos são significados, além de cada significado conferir um momento contextual e histórico, contingencial às regras vigentes. Cada discurso é social e político, constituído em um sistema de relação entre as práticas ou objetos que produzem posições subjetivas com que cada agente social se identifica (HOWARTH, 2000).

Conforme Torfing (2005), o discurso pode ser divido por meio da desconstrução da noção de estruturas totalitárias e por meio da teoria de Derrida (1978), que critica a noção de uma estrutura espacial e geográfica que organiza toda e qualquer estrutura, orgânica e não orgânica, de forma rígida ou pela desconstrução da noção de atomização dos elementos sociais. Com este papel social, o discurso constitui um dos principais elementos sociais.

Gee (1999) evidencia o questionamento sobre a diferença entre discurso e Discurso, e que, para ele, Laclau e Mouffe (1985) são claros ao afirmarem que o Discurso equivale efetivamente à prática social. Portanto, este artigo buscou compreender o discurso da mídia (desde 2006 com a chamada crise aérea) como uma forma de alcançar a prática social por trás deste importante aspecto como uma das peças para a construção do discurso do caos aéreo. A pergunta central a ser respondida pelo estudo foi: como o discurso da mídia está significando a crise aérea? Para responder a essa questão foi necessário entender o discurso e também buscar responder questões relevantes para compreender como a mídia local significa a crise aérea no Brasil. Dessa forma, foi questionado: Quais eram os principais sujeitos envolvidos no discurso da mídia sobre a crise? Como os principais discursos foram tratados? Onde os discursos foram mais intensos? Todas as demandas foram tratadas imparcialmente? 


\section{PANORAMA DA MÍDIA BRASILEIRA}

Segundo Barbosa (2007), até a virada do século XIX ao XX, no cenário nacional, os jornais do Rio de Janeiro foram centrais e passaram por múltiplas configurações. A partir da Coroa Portuguesa, o primeiro jornal impresso na cidade, o Gazeta do Rio de Janeiro, publicado a partir de 1808 pela Imprensa Régia, passou a circular junto a Família Real fugida da Europa. Aqui, a imprensa dividiu-se entre oficial e oficiosa. Oficiosa porque reproduzia a fala oficial para se beneficiar das cercanias de poder. Já com a fundação da Aurora Fluminense, em 1827, houve mudanças e em 1870 surgem discussões sobre abolicionismo e república. Na década de 1880, a política vai às ruas, com debates e agitações populares. Barbosa (2007) diz que a imprensa brasileira nessa época já servia como controle social e agia como veículo de manutenção da ordem vigente.

Ainda nesse período, a imprensa teve a função de apresentar notícias sobre os âmbitos cinematográficos, fonográficos, sobre gramofone e outras tecnologias que passaram a fazer parte do cotidiano da sociedade, como o Jornal do Brasil que em 1894, relatou sobre o kinetoscópio - um objeto capaz de ver imagens em movimento. Em 1901, esse mesmo jornal noticia sobre uma máquina capaz de realizar simultaneamente uma tiragem de seis a oito páginas do jornal por vez. Já em 1902, Barbosa (2007) diz que o Correio da Manhã veicula notícias sobre a política internacional. Esse processo de transformação histórica continua em 1907, quando uma máquina importada da Alemanha, capaz de imprimir em cinco cores, é trazida ao Brasil. Além disso, os cronistas surgem com as revistas críticas - entre 1900 e 1920. Daquela época ainda circulam O Fluminense e O Estado de São Paulo.

A imprensa, com o Golpe de Estado em 1937, passa a ser perseguida e o Estado controla o que saía nos jornais através de uma carta constitucional, que tornou a imprensa um serviço público, sujeita a controle. Isso se reforçou em 1939 com a criação do Departamento de Imprensa e Propaganda (DIP), capaz de censurar toda a produção jornalística, cultural e de entretenimento, além de produzir conteúdos e controlar o abastecimento de papel. Foram vetados pelo Governo 420 jornais e 346 revistas (JORNAL ON LINE, 2008).

Com a chegada dos militares ao poder em 1964, o autoritarismo aumenta. No golpe militar, houve respaldo por parte dos jornais brasileiros à tomada de poder. Contudo, com o tempo, os jornais assumem uma postura crítica ao regime. Mais uma vez, a imprensa sofreu, com a então edição do Ato Institucional no 5 (AI-5), que em 13 de dezembro de 1968 teve pelo regime militar a censura direta e indireta. Isso ocorreu através de ameaças e vigilância 
sobre jornalistas e editores, além de pressões econômicas por meio de verbas publicitárias oficiais ou aos anunciantes privados (JORNAL ON LINE, 2008). Nesse ambiente, Rubim e Azevedo (1998) explicam que, a ditadura militar reprimiu as interações entre política e mídia.

Com o início da redemocratização no Brasil, a partir de 1985, e com a promulgação da Constituição de 1988, o princípio da liberdade de imprensa foi consolidado. A importância do papel da imprensa pôde, enfim, ser constatado na cobertura, pela imprensa, das denúncias de corrupção durante o Governo do presidente da República, Fernando Collor de Mello, o primeiro presidente eleito pelo voto direto após a redemocratização. As denúncias levaram os brasileiros às ruas para protestar, exigir o seu afastamento com papel determinante da mídia.

\subsection{Notícias e Aparências}

Sobre os estudos da comunicação, o seu objeto tem sido pensado, desde o início, em consonância com a caracterização e a análise de novas práticas comunicativas que despontam com o uso cada vez mais frequente e penetrante da tecnologia midiática (SANTOS e SILVA, 2012). O surgimento de novas mídias como a TV por assinatura e a internet reorganizaram o jornalismo tradicional. Alguns jornais brasileiros deixaram de existir em versões impressas, não só por causa do surgimento dessas novas mídias mas por problemas financeiros, ou por perseguições na ditadura militar (JORNAL ON LINE, 2008).

O trabalho de analisar o discurso da mídia - sobre a crise aérea brasileira - ultrapassa o limite do tradicional, pois diferentes tipos de discursos são apresentados, ao mesmo tempo em que uma sociedade recebe dos meios de comunicação um bombardeio de imagens, símbolos e sons, como elementos interagentes de um grande sistema (FREITAS, 1999). São mensagens que abordam (a)eticamente, elementos significativos explícita e implicitamente.

A cultura da mídia também "fornece o material com que muitas pessoas constroem o seu senso de classe, de etnia e raça, de nacionalidade, de sexualidade, de nós e eles. Ajuda a modelar a visão prevalecente de mundo e os valores mais profundos: define o que é considerado bom ou mal, positivo ou negativo, moral ou imoral” (KELLNER, 2001, p. 9). O estudo do discurso midiático, em um caráter sócio-histórico, traz elementos do dito e do não dito que constituem determinado período, como no caso da crise aérea. Assim, "para se compreender o significado do que foi dito e o que foi pressuposto ou implícito, bem como quais foram as reais intenções dos enunciantes, faz-se necessário conhecer o não dito, ou seja, se ler nas entrelinhas do discurso". Além do dito, os elementos linguísticos, extralinguísticos apontam para o que é camuflado ou subtendido numa realização discursiva (FREITAS, 1999). 
Freitas (1999) ainda afirma que a deontologia da comunicação social, nos manuais jornalísticos, orienta que o jornalista ao relatar um fato, deveria ser imparcial e objetivo, porém, Rossi (1986) expõe o mito dessa imparcialidade, pois entre o fato e a versão que é publicada, há a mediação de vários atores (cúpula da organização, empresas) e jornalistas. Ele ainda explica que na busca do que seria objetividade da mídia, existe a orientação de ouvir as duas partes envolvidas no fato, objeto de análise. Com as declarações de ambos os lados, o veículo estaria sendo objetivo, porém, na prática, pode ocorrer um desequilíbrio em um ou para um dos lados e que dessa questão o leitor chegue a raciocinar a partir de dados falsos. $\mathrm{O}$ contexto influencia o discurso e é preciso examinar quais as maneiras pelo qual o acesso ao discurso é regulado por quem detém poder, já que a mídia de massa tem acesso, segundo Van Djik (2010), à notícia e a sua produção, assim como quem está sendo entrevistado, quem assiste, ou quem acessa determinado portal na internet, de quem é levado a sério.

Santos e Silva (2012, p. 3) "para uma sociedade de controle, assente no excesso de informação, na estimulação dos desejos, a exaltação da cordialidade e do humor e na crescente importância dada aos fatores humanos presente na demanda por subjetividades". Segundo Freitas (1999, p.30), "por ser um produto da indústria cultural, existem dentro da estrutura da redação e edição de uma notícia verdadeiros labirintos, que atuam como filtros da notícia" que segue até a figura do editor. Nesse contexto, conforme Kellner (2001, p. 9), “a cultura da mídia é industrial; organiza-se com base no modelo de produção de massa e é produzida para a massa de acordo com tipos (gêneros), segundo fórmulas, códigos e normas convencionais. É portanto, uma forma de cultura comercial, e seus produtos são mercadorias que tentam atrair o lucro privado produzido por empresas gigantescas que estão interessadas na acumulação de capital”, que almeja audiência. Lucien Sfez (2007) diz que a comunicação se tornou refém da tecnologia. "Esse discurso sobre a técnica invadiu a totalidade das atividades humanas, inclusive a comunicação" (p.19). Segundo ele, a discussão não se coloca no modo de produção capitalista e no desenvolvimento de uma indústria cultural a ele correlata, mas simbolicamente em que a tudo e a todos aprisiona ancorada na técnica.

\subsection{Mídia, Sociedade e a Produção de Notícias}

Fairclough (2008, p.122), diz que "hegemonia é liderança, tanto quanto dominação nos domínios econômico, político, cultural e ideológico de uma sociedade. É o poder sobre a sociedade como um todo de uma das classes economicamente definidas como fundamentais em aliança com outras forças sociais, mas nunca atingindo senão parcial e temporariamente, como um equilíbrio instável”. Mesmo com as notícias do rádio, televisão, internet e mídia 
impressa, os leitores podem ter se tornados mais críticos e independentes, porém, Van Dijk (2010, p.21), diz que "a ilusão de liberdade e diversidade pode ser uma das melhores maneiras de produzir a hegemonia ideológica que servirá aos interesses dos poderes dominantes na sociedade, incluindo as empresas que fabricam essas próprias tecnologias e seus conteúdos midiáticos e que, por sua vez, produzem tal ilusão". Conforme Fairclough (2008), a ideologia interpela os sujeitos e os conduz à concepção de que um dos efeitos ideológicos mais significativos é a constituição do sujeito. Sobre esse ponto, Peruzzo, Tufte e Casanova (2011) explicam que ancorados nos conceitos de cidadania, é impossível pensar a formação de uma cultura política cidadã à margem dos meios massivos de comunicação. Segundo Veloso e Farias (2011, p.29), “a relação cada vez mais desvirtuada entre Estado e empresários originou a formação dos gigantes da mídia no mundo e fundamentou a prevalência de interesses privados sobre bens que deveriam ser públicos".

Pelo controle da mente pela mídia, deve haver também o controle dos detalhes discursivos e interacionais dessa produção, já que as pessoas são influenciadas pelas notícias que leem ou veem. Sfez (2007), diz haver um movimento circular sem referencialidade com o real no qual o excesso de informação anula o sentido, e, por conseguinte, a comunicação. Segundo o autor, a comunicação implode no excesso de informação.

Conforme Paulino, Coelho, Mendes e Pedrosa (2011, p. 82), a comunicação, “deve ser considerada como um meio de troca, onde o diálogo sobrepõe o monólogo. Essa troca democrática não é respeitada devido a monopolização por grupos específicos. Calcula-se hoje que, no Brasil, cerca de $80 \%$ do que é veiculado na mídia, é controlado por apenas sete grupos". Os autores dizem que a internet como o meio da democratização da comunicação, pode tomar o mesmo caminho de outros meios que "já foram considerados dessa forma, como o rádio e a televisão, já que a tendência é a sua comercialização” (p.82). Sfez (1995 e 2007), invoca o fim da comunicação, pois se percebe que a comunicação não tem mais objeto e existência. Dessa forma, há tantos meios de comunicação, porém, entendemos cada vez menos. Por isso, Van Dijk (2010, p.28) diz que a mídia mais desinforma do que informa, pois "podemos esperar que a mídia de massa nos informe sobre distúrbios civis, mas quando é exatamente que essa informação sobre distúrbios se transforma em textos apontam um legítimo culpado, ou sobre uma ideologia acerca da verdade? Quem define o que é legítimo?”

Santos e Silva (2012, p.11) dizem que "a comunicação anda de mãos dadas com a técnica e juntas elas se oferecem com a voz única, servindo como suporte discursivo em diversas áreas do conhecimento, que vão da inteligência artificial ao marketing e à publicidade". Sobre isso, Van Dijk (2010) diz que dentre as formas de texto impresso os 
meios de comunicação de massa são os mais penetrantes, mais influentes, a se julgar pelo número de receptores, pois segundo o autor, ao contrário da crença popular e senso comum, esses tipos de notícias são mais bem lembradas do que as notícias de televisão e são percebidas como qualitativamente superiores devido ao seu acesso não ser em um único momento. VAN DIJK (2010), diz que devido a sua socialização e pertencimento a uma classe, os jornalistas tendem a reproduzir as ideologias dominantes da elite.

Porém, Freitas (2011, p. 341) afirma que, "mesmo que se reconheça a quase impossibilidade de presenciarmos a democratização da mídia comercial e privada brasileira, é preciso que atores até então invisibilizados contemplem o que está sendo produzido no e pelos meios de Comunicação sobre si. Mesmo que constatemos que a decisão sobre o que é produzido pela grande mídia por grupos invisibilizados seja uma utopia, não podemos desconsiderar: o fortalecimento da Comunicação comunitária, a multiplicação de veículos de informação populares, alternativos, livres e independentes".

\subsection{Setor Aéreo Brasileiro}

O homem há muito tempo deseja voar, pois desde Ícaro a Leonardo Da Vinci inúmeras foram as tentativas. No início do século XX, Alberto Santos-Dumont conseguiu decolar, planar e pousar com um protótipo do avião e marcou a história da aviação no mundo. Na I Guerra Mundial (1914-1918), o avião foi utilizado como uma arma militar e com o fim dessa guerra a indústria aeronáutica focou seu avanço tecnológico na seara militar. Entretanto, no fim da II Guerra Mundial (1939-1945), o mercado militar entra em crise devido a diminuição da demanda por aviões e a área civil tornou-se o melhor mercado para sua expansão.

Nas décadas seguintes, o transporte aéreo mundial se modernizou e passou a buscar mais conforto e segurança aos passageiros. No Brasil, a aviação civil foi iniciada em meados de 1920 e o movimento aéreo passou a ser de crescimento. A relação do povo brasileiro com o mercado da aviação civil foi significada também por fatores, dentre eles, a queda do preço das passagens em torno de $48 \%$ entre 2003 a 2008. Além disso, o crescimento no uso dos civis no setor, só em 2010 subiu para cerca de 50 milhões de viagens (MCKINSEY \& COMPANY, 2010). Na atualidade, partem e chegam diversos voos nacionais e internacionais. Desde 2009 são registrados mais de 74 milhões de embarques no Brasil feitos exclusivamente por empresas aéreas nacionais. Destes, 71 são domésticos e mais de 2 milhões são internacionais. 
As empresas tradicionais - Serviços Aéreos Cruzeiro do Sul, TransBrasil, VASP e VARIG - foram, no fim da década de 1990 e início de século XXI, substituídas pela TAM e a GOL Transportes Aéreos Ltda, que emergiram como novos líderes no mercado nacional. Porém, em 2006 iniciou a chamada crise aérea no Brasil. Essa crise, ou apagão aéreo, ocorreu devido um desastre aéreo de grandes proporções, vitimando 154 pessoas, envolvendo a empresa GOL transportes aéreos - voo 1907 com destino Manaus-Brasília - e a norte americana ExcelAir - em um jato Legacy - de táxi aéreo, apresentando publicamente uma fragilidade administrativa entre a categoria dos controladores de voos e sua classe patronal, a Aeronaútica Militar (VIA JUS, 2013). Em outubro do mesmo ano, uma pane nos radares do Cindacta 2 (Curitiba) atrasou 145 voos. Já em novembro, os controladores de voo iniciaram um protesto - devido a falta de infraestrutura como sucateamento dos equipamentos e carga horária excessiva de trabalho - que atrasou decolagens e pousos. Em dezembro, foram registrados os maiores atrasos, com filas, confusões e revolta dos passageiros.

O que se conhece hoje como caos aéreo é uma consequência de um crescimento desordenado e desproporcional em relação ao número de usuários de voos, vendas excessivas de passagens em relação a capacidade das aeronaves, planos desregulados no que diz respeito a perspectiva de compra de mais aeronaves por parte das empresas e, por outro lado, a falta de investimento em infraestrutura por conta do Estado para dar suporte a este mesmo crescimento. Um colapso que foi desenhado ao longo dos últimos vinte anos, passou por acontecimentos envolvendo a VARIG em 2003 e em 2006 com a GOL (SALGADO, 2009). Outros episódios em 2006 tornaram mais visível a situação estrutural deficitária e conflituosa entre os agentes que integram o setor de transporte aéreo nacional, como a "greve branca" dos controladores ocorrida no feriado de Finados e da "Proclamação da República".

Contudo, apesar de marcas que a governança do setor aéreo brasileiro estava passando por profundos problemas estruturais (SALGADO, 2009), a Aeronáutica negou a existência de tais problemas, mesmo quando diversos órgãos de imprensa nacional divulgaram amplamente o caso. Todavia, a falta de recursos públicos - no que diz respeito aos aeroportos - ou a sua má administração para prover uma boa estrutura aos aeroportos para que possam atender esta demanda crescente, a escassez de mão de obra de controladores de tráfego aéreo aliada às precárias condições de trabalho, as falhas técnicas como as "zonas cegas" dos radares, são exemplos destes componentes que comprometem todo o sistema (SALGADO, 2009).

Adiciona-se a este cenário, já caótico do ponto de vista estrutural, uma atividade possível por meio de concessão pública, como é o transporte aéreo nacional, regulado por meio da lei 8.987/95, que admite como agentes, organizações economicamente orientadas e 
que possuem uma racionalidade diferente dos agentes regulamentadores. A existência de um mercado em que coexistem serviços públicos essenciais e organizações economicamente orientadas sugere que seja conceitualmente entendido como um campo da teoria da regulação (ARAGÃO, 2009; CRUZ, 2009), em que o debate central é o "tamanho" do Estado.

Diversos sujeitos estão envolvidos com o mercado da aviação civil nacional, tais como o Ministério da Defesa - órgão responsável pela aviação no Brasil - e que é comandada pela Força Aérea Brasileira (FAB), que por sua vez não responde sozinha pelo gerenciamento do setor, contando com a Empresa Brasileira de Infraestrutura Aeroportuária (INFRAERO) uma empresa estatal e tem a principal finalidade de administrar os aeroportos do Brasil - além da Agência Nacional de Aviação Civil (ANAC) - responsável pela regulação e fiscalização das atividades de aviação civil e de infraestrutura aeronáutica e aeroportuária. O detalhe é que a ANAC é a única dessas entidades que é comandada por uma autoridade civil. Na visão do mercado, o Conselho Administrativo de Defesa Econômica (CADE) regula essa estrutura.

Afora a pluralidade de sujeitos públicos que estão envolvidos no mercado da aviação civil, diversos problemas de ordem técnica/operacional surgem como complicadores da gestão do espaço aéreo nacional, que é de responsabilidade da FAB, tais como obsolescência dos aparelhos que controlam o tráfego aéreo gerando "zonas cegas" de controle, a diversidade de frequências de rádio utilizadas para a comunicação entre os Centro Integrado de Defesa Aérea e Controle do Espaço Aéreo (CINDACTA), que não oferecem clareza para a comunicação, o número reduzido de controladores, necessitando aumentar em 800 o seu número, dentre outros problemas estruturais que comprometem a segurança do transporte aéreo nacional.

\subsection{Caminhos Metodológicos}

A TD é utilizada para compreender os significados socialmente construídos e exige uma perspectiva mais abrangente do fenômeno. Dessa forma, na TD, os processos metodológicos podem, em parte, ser menos importantes. O que não quer dizer que essa abordagem pretende o anarquismo metodológico. Seu objetivo é produzir novas interpretações de fenômenos antes não identificados por outras teorias ou propor uma problematização alternativa para descrições existentes (HOWARTH, 2005).

A TD ofereceu ferramentas ou conceitos chaves para a análise do discurso da mídia entendendo-o como fruto de discursos formados por sistemas relacionais de significação e prática que constrói identidades e posições de sujeito (HOWARTH \& STAVRAKAKIS, 
2000). Aqui, o conceito de articulação assume papel central na medida em que trata da articulação entre técnicas e métodos que permitem a análise crítica de determinado fenômeno.

Para discussão do problema do estudo, foi necessário a construção de um corpus com elementos apropriados para a análise. Na perspectiva de Sinclair (1991), um corpus seria uma coleção de textos naturais ou autênticos escolhidos para caracterizar um fenômeno. Seguindo as orientações de Minayo (2000), o corpus desta pesquisa seguiu as normas de exaustividade, homogeneidade representatividade e pertinência: certificou-se de que o material contemplou todos os aspectos levantados no roteiro, englobou as características essenciais ao universo pretendido, obedeceu a critérios precisos de escolha quanto aos temas tratados, às técnicas empregadas e atributos dos interlocutores, mostrando-se adequados aos objetivos do trabalho.

O corpus foi composto por 33 provedores privados e 10 blogs. Os provedores privados foram: UOL, G1, Revista Consultor Jurídico, Folha de notícia, Terra, Estadão, ETC, Portal Pravda, Causa Operária, Folha on line, Observatório da Imprensa, Infovias, Revista em discussão, IG, Ucho.info, Sidneyrezend, Veja, Melhores Destinos, Jornal do Comércio, Jornal da Mídia, Gazeta do Povo, Poder Aéreo, Correio Braziliense, CBN, Agência Brasil, Exame, Info online, Istoé, OEXPRESSO, Última Instância, Zero Hora. Os blogs analisados foram: Ida\&Volta, Revista Forum, Air Brazil, Blog do Rizzatto Nunes, Cora Ronai, Alunos do Ide, Blog do Rizollo, Blog Cristine Fontenelle, Blog da Helena e Liga estratégica Revolucionária - LER. Foram analisadas um total de 113 notícias.

\begin{tabular}{|c|c|c|c|c|c|c|c|c|}
\hline \multicolumn{8}{|c|}{ Quantidade de Notícias por Ano } \\
\hline Ano & 2006 & 2007 & 2008 & 2009 & 2010 & 2011 & 2012 & 2013 \\
\hline Notícias & 9 & 27 & 11 & 14 & 8 & 9 & 14 & 21 \\
\hline \multicolumn{8}{|c|}{ Quadro 1. Quantidades de notícias x ano } \\
Fonte: elaboração própria
\end{tabular}

A análise do fenômeno, de tradição crítica, foi realizada através da Análise do Discurso $(\mathrm{AD})$ que examina uma variedade de materiais e informações empíricas, tendo como conceitos chaves para entender o fenômeno a Teoria do Discurso (TD) de Laclau e Mouffe (1985). Desse modo, procurou-se uma conjunção de métodos e técnicas na tentativa de dialogar e convergir com os pressupostos da TD (GLYNOS \& HOWARTH, 2007). O caminho teórico de Laclau e Mouffe possui como característica central a natureza polissêmica dos agentes sociais e de suas lutas. Essa direção argumentativa foi relevante para analisar os significados, a formação de cadeias de equivalência e os antagonismos do discurso da mídia brasileira sobre a Crise Aérea. As análises foram realizadas e organizadas cronologicamente 
(2006 - 2013) notícia por notícia, provedor por provedor, para que assim fosse possível observar as diferenças entre os discursos dos provedores e suas mudanças ao longo dos anos. Os resultados apresentados (analisados de julho a novembro de 2013) seguem esta lógica.

\subsection{Posições dos Sujeitos Acerca da Crise Aérea}

$\mathrm{Na}$ obra de Laclau, o sujeito resiste e interage nas suas relações sociais. Articula-se e transforma-se na tentativa de criar formas de ver o mundo. Nesse processo os significados são negociados, fazendo-se e refazendo-se permanentemente em busca de hegemonia. Observaram-se 35 pontos de resistência e luta pela hegemonia: UOL, G1, Revista Consultor Jurídico, Folha de notícia, Terra, Estadão, ETC, Portal Pravda, Causa Operária, Folha on line, Observatório da Imprensa, Infovias, Revista em discussão, IG, Ucho.info, Sidneyrezend, Veja, Melhores Destinos, Jornal do Comércio, Jornal da Mídia, Gazeta do Povo, Poder Aéreo, Correio Braziliense, CBN, Ida\&Volta, Revista Forum, Air Brazil, Blog do Rizzatto Nunes, Cora Ronai, Alunos do Ide, Blog do Rizollo, Blog Cristine Fontenelle, Blog da Helena e por fim a Liga estratégica Revolucionária - LER. Esses sujeitos aparecem e desaparecem no discurso ao longo dos anos analisados. Em cada ano os sujeitos se posicionam na tentativa de significar a crise aérea no Brasil.

Com base nas seguintes notícias foi possível perceber que os portais G1 e Estadão, foram os que mais se posicionam. No discurso do G1, o sujeito Governo é sempre visto como culpado pela crise. O Estadão, por outro lado, se apresenta como portal que considera as empresas aéreas como culpadas pela crise. Não foi possível identificar aqui o início de um antagonismo no discurso, mas cadeias de diferenças marcantes nos discursos do G1 e do Estadão quanto a quem são os responsáveis pela crise. 


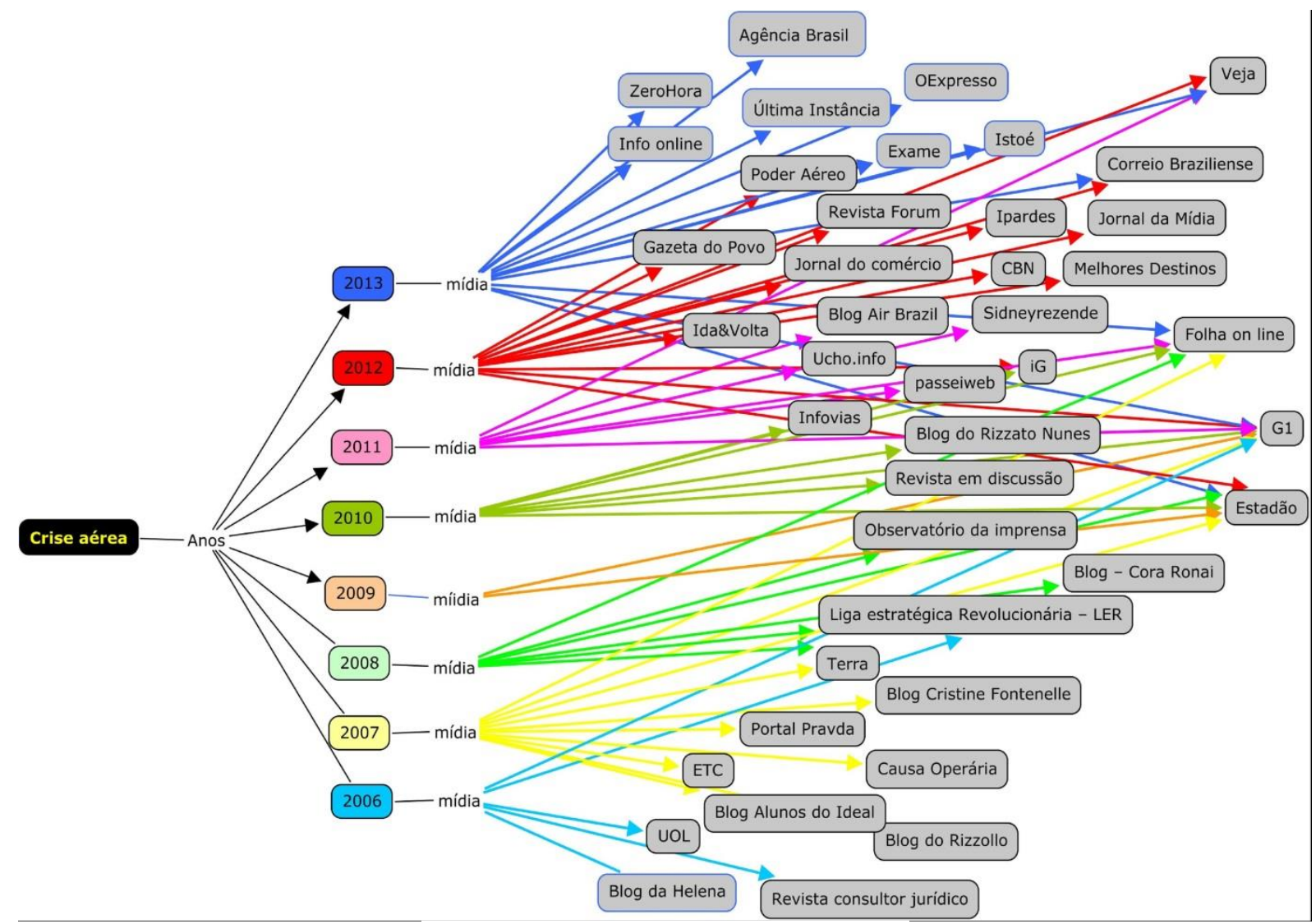

Figura 1. Sujeitos e frequência do discurso

Fonte: elaborado a partir do software CmapTools versão 5.05.01

O antagonismo é a condição de possibilidade da própria constituição discursiva. Segundo Laclau (1996), ao mesmo tempo em que o exterior constitutivo (discurso antagônico) ameaça a constituição do interior (discurso antagonizado), ele é também a própria condição da existência do interior, na medida em que esse último se constituiu sob a ameaça da presença do primeiro, uma vez que a presença sempre constante de um impede a constituição completa do outro. Tratam-se, assim, de constituições identitárias sempre incompletas, contingentes, precárias e ameaçadas: a presença do outro me impede de ser totalmente eu mesmo. Isso quer dizer que a produção de sentidos pelo interior discursivo está limitada pelo exterior antagônico.

O caminho teórico, que Laclau e Mouffe oferecem, coloca como característica central a natureza polissêmica dos agentes sociais e de suas lutas. Essa direção argumentativa nos parece relevante para analisar os significados, a formação de cadeias de equivalência e a busca por antagonismos em um discurso que ecoa na sociedade em torno da crise aérea no Brasil, mas, principalmente, o discurso da mídia sobre a crise aérea. A cada ano as posições dos sujeitos aparecem com maior ou menor frequência no discurso e, muitas vezes, essas posições se diferenciam como pôde ser visto no Quadro 2. 


\begin{tabular}{|c|c|}
\hline \multicolumn{2}{|r|}{2006} \\
\hline \multicolumn{2}{|r|}{ UOL } \\
\hline Grupos & Atores \\
\hline Governo & Infraero, Aeronáutica, Cindacta -1, Cindacta-2, ANAC, Polícia Federal, controladores \\
\hline Empresas & GOL, Legacy, \\
\hline Sociedade & Passageiros \\
\hline \multicolumn{2}{|r|}{ G1 } \\
\hline Grupos & Atores \\
\hline \multirow{6}{*}{ Governo } & Casa Civil, Ministério da Defesa, Conselho de Aviação Civil, Aeronáutica, \\
\hline & Infraero, Centro de controle de tráfego aéreo de Brasilia, ANAC \\
\hline & Controladores de vôo, Gerenciamento de Navegação aérea, \\
\hline & Região de Informação de vôo (AFIR), Aeroporto Tom Jobim, \\
\hline & Cindacta, Presidência, Ministerio da fazenda \\
\hline & Aeronáutica, Militares, Lula, Forças Armadas, Aeroporto Guarulhos \\
\hline Empresas & BRA, TAM, GOL, Varig, Vasp, Gol, Fantástico, \\
\hline Sociedade & ONG Contas Abertas, passageiros \\
\hline Sindicatos & Sindicato Nacional dos Trabalhadores de Proteção ao Vôo \\
\hline \multicolumn{2}{|r|}{ Blog - Liga estrategia Revolucionaria } \\
\hline Grupos & Atores \\
\hline Governo & $\begin{array}{l}\begin{array}{l}\text { Aeronáutica, Militares, Presidência, Forças Armadas, Aeroporto } \\
\text { controladores }\end{array} \\
\end{array}$ \\
\hline Empresas & GOL, Legacy, \\
\hline Sindicatos & CUT \\
\hline \multicolumn{2}{|r|}{ Revista consultor jurídico } \\
\hline Grupos & Atores \\
\hline Governo & \begin{tabular}{|l|} 
União, Anac, Conac, Ministério da Defesa, comando da aeronáutica, Infraero, \\
Anac, Tribunal de Contas da União (TCU)
\end{tabular} \\
\hline \multicolumn{2}{|r|}{ Blog da Helena } \\
\hline Grupos & Atores \\
\hline Governo & ANAC, Força Aérea, Presidência, Embraer, Congonhas, Cumbica \\
\hline Empresas & TAM \\
\hline
\end{tabular}

Quadro 2. Sujeitos que mais aparecem nos discursos das mídias Fonte: elaboração própria

No ano de 2006, o site UOL tratou do acidente entre GOL e Legacy, do embate entre alto escalão da Aeronáutica e os controladores e enfatizou os "pontos cegos" não registrados pelos equipamentos de controle de voos. Devido a isso, os controladores passaram a seguir as regras de voo internacionais, o que gerou cancelamentos e atrasos. Já a polícia Federal culpou os pilotos americanos do Legacy e os controladores pelo acidente. O site G1, em suas notícias reforçou a falta de investimento para o setor aéreo e que o Governo buscou contratar controladores aposentados e recém-formados, o que não é aceito pelo Sindicato dos controladores que achou perigosa essa postura do Governo Federal e assim pedem aumento salarial além da melhoria nas condições de trabalho. A Aeronáutica culpou as empresas e os controladores reclamam dos equipamentos arcaicos, mas a Embratur - Empresa Brasileira de Turismo, minimizou ao divulgar que a crise não afetaria a economia do turismo no Brasil. Já O blog Liga Estratégica Revolucionária - LER, apontou para o fato de que os controladores foram injustiçados como culpados pela crise, e que o problema era do sucateamento dos equipamentos e defendeu a desmilitarização do setor aéreo nacional. Já o Blog da Helena, apontou para a posição da ANAC em proibir empresas sobre overbooking - venda de passagens além da capacidade do avião - e mostrou que a Presidência da República cobrou à 
ANAC e as empresas. O blog informou que o Governo Federal colocou aviões da FAB para minimizar atrasos e cancelamentos, principalmente da TAM.

A Revista consultor jurídico, disse que Governo e empresas foram culpados pela crise, com má prestação de serviços. Os sites privados GOL e UOL apontaram para culpa do Governo e desarticulação para tal solução, ao passo que os blogs indicaram desmilitarização do setor e apontaram que os controladores não foram culpados pela crise.

Em 2007, o discurso do G1 reforçou que os controladores eram culpados pela crise, que isso afetaria o turismo e devido a isso as pessoas tenderiam a buscar viagens de ônibus ou carro. Disse ainda que os controladores culparam a falta de infraestrutura e apontaram falhas no Cindacta-1, em Brasília. O site apontou para o sistema de tráfego aéreo falho e disse que o Governo definiu a crise como um "falso terrorismo". Esse portal de notícias explicou que a crise dava prejuízo as empresas e que a Cúpula da Aeronáutica continuava a culpar os controladores. Informou ainda que as ações das empresas tinham aumentado, mas devido ao acidente temiam perder clientes. No fim do ano, o portal G1 lembrou que o Governo não agiu e contratou apenas $10 \%$ dos controladores necessários.

O site Folha de Notícia indicou a mudança de controle da TAM - considerada culpada pela crise. O portal Terra explicou que os controladores foram menosprezados por parte da cúpula da Aeronáutica e Governo. O Estadão indicou que o mau tempo atrapalhou as empresas aéreas e por isso houve cancelamentos e atrasos, mas que com controladores contratados a crise seria solucionada. Culpou ainda o Governo e disse que o mesmo deveria ceder a lógica privada para solucionar a crise.

O portal ETC, disse que Governo Federal e empresas aéreas eram culpadas pela crise e que esta não teria fim. O Governo foi omisso e Congonhas considerado o principal problema. A TAM e GOL foram consideradas as principais causadoras da crise e a Infraero não agiu para construção de novos aeroportos e terminais. O site Causa Operária, afirmou que a TAM foi culpada pelo acidente devido falta de manutenção nos aviões e ganância (overbooking) e que o Estado deveria se posicionar.

Os blogs tiveram posições diversas em 2007, mas tenderam a culpar as empresas pela crise. O Blog Cristine Fontenelle criticou as empresas com ênfase na GOL por propaganda enganosa e disse ser injustiça culpar os controladores. Os Blogs do Rizollo, assim como o Observatório da Imprensa, acusaram a mídia de sensacionalista em relação a crise e focaram na Rede Globo como manipuladora. Já o Blog Alunos do Ideal se posicionaram em relação à estrutura do controle aéreo como precária. Por fim, o Portal Pravda explicou que o Governo encontrou fraudes nas obras em aeroportos. “A relação antagônica se estabelece na medida 
em que a presença do "outro" não permite que o "eu" seja completamente "eu"” (PINTO, 1999, p. 84). Dessa forma, percebe-se que a simples presença de um "outro" impede a total constituição de um “eu”, caracterizando um antagonismo entre mídia privada e blogs.

Em 2008, o discurso da Liga Estratégica Revolucionária - LER apontou para uma posição mais crítica pelo fato de que as empresas TAM e GOL formaram um duopólio, demitiram funcionários e o Governo assim como ANAC foram cooptados pela lógica do Capital. Disse também que a Central Única dos Trabalhadores - CUT perdeu sua força porque os representantes cederam a lógica do Governo. De forma similar, o Observatório da imprensa disse que a mídia foi sensacionalista e tendenciosa com a crise. O portal Terra indicou que a TAM se articulou com ABAV - Associação Brasileira de Agências de Viagens - para aumentar o preço das passagens e repassar o aumento para os consumidores.

O Estadão mostrou em suas notícias, que o Governo Federal culpou as empresas pela crise e estas culparam o Governo pela falta de infraestrutura. A Folha Online mostrou que as empresas aéreas perderam valor no mercado por culpa da ineficiência do Governo. Por fim, na visão do Blog da Cora Ronai, houve supremacia da lógica do capital sobre o Governo quando houve a venda da Varig/Log em que o Governo cedeu percentual de venda a uma empresa estrangeira, o que é proibido por lei.

Em 2009, as notícias reforçaram aspectos já citados sobre a crise, mas os passageiros são foram mais enfatizados. Conforme o Estadão, a partir dos aspectos relacionados aos atrasos de voos - com ênfase na GOL - afirmou o fato da ANAC defender mais direitos aos passageiros e que esses sofriam com as condições precárias dos equipamentos e peças com as quais são fabricados os aviões, pois são usuários. Além disso, o Estadão re-enfatizou que os aeroportos operavam em situação precária, pois não havia fiscalização. Além disso, corrobora o já mencionado sobre a ineficiência dos controladores. Os aeroportos, de 2006 a 2009, foram os mais enfatizados sobre a crise aérea.

Em 2010, o portal G1 mostrou que os deputados brasileiros e advogado das vítimas do acidente de 2006 da GOL com jato legacy, tiveram pedido, para cassar licença dos pilotos americanos, negado. O Infovias indicou fragilidade do Governo ao dizer que ABAG Associação Brasileira de Aviação Geral - e INFRAERO concordaram que não havia uma estrutura pronta aeroviária para sediar a Copa do Mundo de Futebol em 2014. A postura do Blog do Rizzatto Nunes, apontou para o descaso para com os passageiros e que a ANAC, desde que foi criada, resolveu essa situação. O portal Revista em Discussão abordou um fato, pouco explorado até então que foi o da desmilitarização do setor aéreo brasileiro. 
O Estadão, disse que as empresas continuaram a fazer overbooking, além do fato dos aeroportos serem despreparados para o atendimento ao consumidor e que a TAM agia contra a crise alocando aviões maiores para atender a região sudeste brasileira. O portal $\mathrm{iG}$ reforçou, ao dizer que as empresas aéreas iriam utilizar 17 aviões extras para não existir crise no fim de ano e que o Governo proibiu prática de overbooking, além do fato da Infraero contratar 922 funcionários em um plano de contingência. Por fim, a Folha On Line, disse que o Governo puniu Sindicato das empresas aéreas pela crise e por overbooking.

Com base nas notícias de 2011, o G1 informou que a Justiça Militar e o Tribunal Regional condenaram controladores a regime aberto pelo fato de inexperiência e inabilidade no inglês para falar com pilotos americanos. Já a Folha de São Paulo repetiu o divulgado pelo G1 sobre a insuficiência intelectual e divulgou que a Justiça federal condenou pilotos americanos como culpados pelo acidente da GOL com pena a cumprir em liberdade. O Ucho.info trouxe um assunto novo à crise que foi o fato de o Governo pensar em privatizar alguns aeroportos. Ainda assim, o site indicou que só isso não resolveria e que o Governo deveria fiscalizar as práticas das empresas contra overbooking e que fossem dadas condições de trabalho favoráveis aos controladores. O site Sidneyrezende - SRZD - informou que Governo criou a Secretaria de Aviação Civil e que a mesma era ligada à presidência e o Ministério da Defesa ficaria responsável pelo controle do espaço aéreo. O site Passeiweb.com, indicou a postura favorável as empresas sobre a falta de investimento do Governo no setor.

A Veja disse que Governo investiu 5,6 bilhões para Infraero melhorar infraestrutura dos aeroportos, porém, em 2014, dos 13 aeroportos que passavam por reformas, apenas o Galeão estaria em condições. O portal indicou que o caos era "insolucionável". Em seguida diz que o Governo sinalizou a privatização de Vira Copos, Guarulhos, Brasília, mas que a privatização não iria solucionar o caos e como solução parcial trabalharia com os módulos operacionais provisórios, conhecidos como "puxadinhos" - mini terminais. Por fim, o blog Air Brazil defendeu os controladores e disse que de acordo com o que o radar apresentava, qualquer especialista também teria tomado a mesma decisão no dia do acidente.

Em 2012, o G1 divulgou que a Presidência em apresentação a empresários franceses afirmou que o mercado brasileiro era propício a investimentos e disse que construiria 800 aeroportos para abrir espaço para outras empresas atuarem no mercado nacional de aviação. $\mathrm{O}$ Estadão, por outro lado, disse que várias obras nos principais aeroportos brasileiros, que seriam feitas em 2013, foram adiadas para depois da Copa do Mundo, devido falta de necessidade imediata, segundo Governo. Ainda disse que foi feita inauguração de uma torre 
de controle em Congonhas, com dois anos de atraso. Nesse ritmo, pistas para taxi, segurança no pouso de aviões e outras obras foram adiadas.

Ainda sobre os atrasos dos voos, a Veja, informou que a Comissão Parlamentar de Inquérito - CPI da crise foi criada para proceder sobre as reclamações de atrasos, cancelamentos de voos, roubo/extravio de cargas e preço diferenciado pelas poltronas. De forma semelhante a Revista Fórum explicou que o Estado não foi controlador em relação às empresas aéreas e às obras feitas pelas construtoras nas pistas dos aeroportos, pois cedeu a pressão das empresas que disseram que as reformas reduziriam os voos e seria prejudicial as mesmas. Congonhas - no meio de residências - é um perigo, mas lucrativo para as empresas.

O site Melhores Destinos apontou que as empresas aéreas se uniram, com direção da GOL e TAM, e fundaram a ABEAR - Associação Brasileira de Empresas Aéreas, no intuito de ter forças contra o Governo. Nesse caminho, o Jornal do Comércio explicou sobre o aumento da demanda que quase triplicou de 2003 a 2011, mas que as empresas não estavam sabendo lidar com custos operacionais e cancelaram rotas, demitiram funcionários e GOL e TAM, juntas, somaram prejuízos de mais de $\mathrm{R}$ \$ 2,5 bilhões. O Jornal da mídia complementou ao afirmar que as empresas estavam em crise, mas de gestão. O blog Ida\&Volta disse que a TAM perdeu rentabilidade e cortou voos para o norte e nordeste, o que ocasionou demissões.

Nessa disputa a Gazeta do Povo disse que empresas culparam o Governo por tarifas altas e altos preços dos combustíveis, o que foi repassado aos clientes. GOL e TAM, com $80 \%$ do mercado passaram a ter prejuízos e Avianca, ao contrário. Porém por falta de investimento do Governo a mesma não atuava em alguns aeroportos, da mesma forma que a portuguesa TAP, que não poderia atuar em Curitiba.

Como ação do Governo para a crise, o site Poder Aéreo mostrou que, como forma de solucionar a crise, Cumbica e Guarulhos teriam pela primeira vez, pistas paralelas que permitiriam pousos e decolagens simultâneos. Atualmente as pistas tem metade do requisitado por norma, que é de 760 metros. Por outro lado, o Correio Braziliense mostrou notícia que, segundo a voz do Governo, os aeroportos não teriam problemas de atrasos, ou cancelamentos durante período de férias e com a saída do mercado da WEBJET, a Gol operaria esse espaço. Nesse sentido, como mais uma ação do Governo, conforme CBN, investimentos foram feitos pela Infraero no aeroporto de Vitória, para atuar sobre pousos, decolagens facilitando o trabalho dos operadores de voo; além de uma máquina de raio-x para acabar com filas no saguão, aumento no estacionamento para automóveis, além da fachada do aeroporto. Muitas dessas obras foram consideradas como "puxadinhos". 
Em 2013, a Agência Brasil enfatizou os estudos realizados pelo Governo para solucionar os problemas nos aeroportos. O Correio Braziliense, por sua vez, chegou a criticar as ações da Infraero revelando uma lógica capitalista de lucro a qualquer custo. O Estadão em todas as suas reportagens enfatizou a opinião da Infraero e as ações do Governo para solucionar a crise aérea. A Exame revelou nesse ano, a situação precária dos aeroportos brasileiros. A Folha Online enfatizou o estado de crise do setor aéreo, alertou para crises futuras e para ineficiência do Estado. O G1, enfatizou as dificuldades na construção e reforma de aeroportos para a Copa do Mundo de 2014. A Info Online em todas as suas notícias enfatizou as ações do Governo para vencer a crise e melhorar os aeroportos. Já a Istoé, criticou o Governo e a Infraero, denunciando corrupção e desvio de verbas nas reformas dos aeroportos. O jornal online OEXPRESSO enfatizou as condições precárias dos aeroportos e a falta de investimentos. Última Instância foi o único portal em 2013 que citou o consumidor e seus prejuízos com a crise. A Veja online, enfatizou a ação da justiça para evitar a corrupção nas reformas dos aeroportos.

O Zero Hora, por sua vez, também comentou sobre as construções e reformas dos aeroportos, reafirmando as dificuldades do Governo em solucionar esses problemas. Em sua maioria, as notícias analisadas focaram mais nas ações do Governo para melhorar a crise, além do silêncio e da falta de iniciativa das empresas na procura de sair do caos no qual o setor aéreo se encontrava. Na figura 2 é possível visualizar as palavras mais citadas nas reportagens de 2013, com ênfase nos aeroportos e no caos aéreo, principalmente o aeroporto de Congonhas.

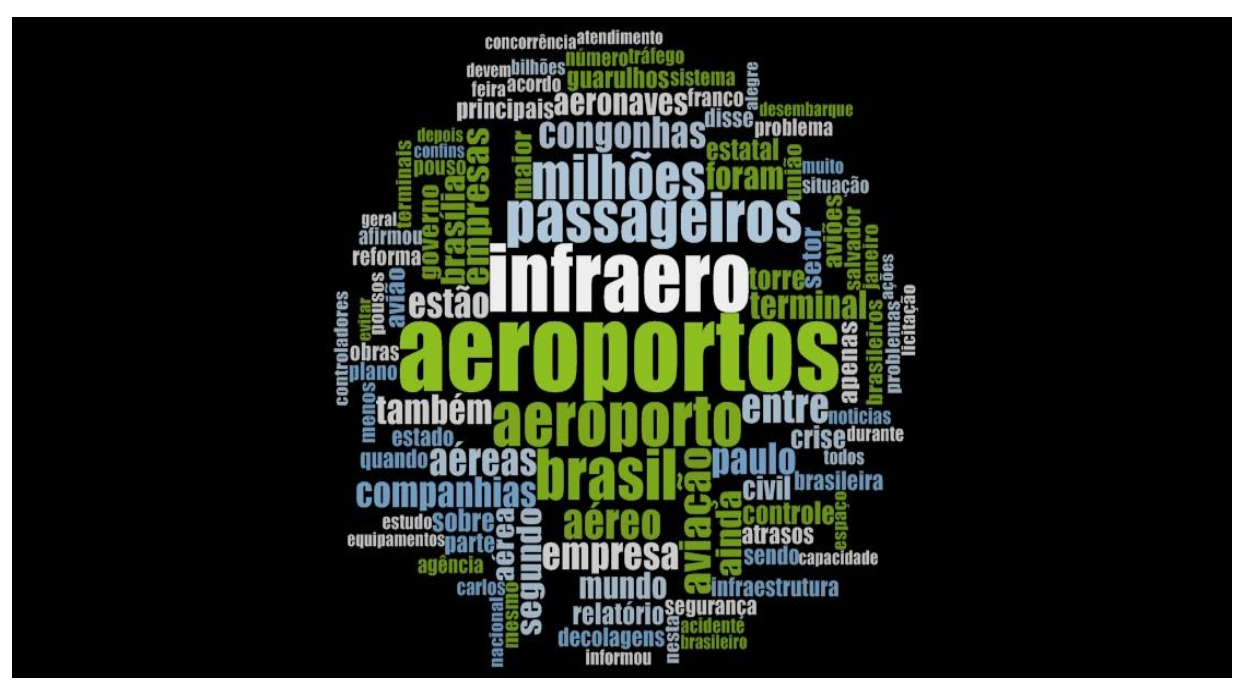

Figura 2. Aspectos que mais significam a crise aérea em 2013 Fonte: elaboração a partir do software Nvivo 
No que diz respeito a uma cadeia de equivalência é possível perceber a Veja e o G1, pois aquele portal também julga o Governo culpado pela crise. Em todos os anos, os blogs se apresentam no intuito de considerar os controladores (sujeitos) de voos injustiçados pela Aeronáutica e Governo. A partir de 2011, a mídia passa a tratar do processo de privatização dos aeroportos, mas considerou que a privatização não era solução para a crise aérea. Mesmo com a discussão em torno da má gestão do setor aéreo pelo Governo, apenas uma notícia explicitou a indicação de um processo de desmilitarização do setor aéreo. Como foco geral das reportagens, ficam bem definidos dois posicionamentos ao considerar a crise, que de certa forma acompanham os posicionamentos do G1 e do Estadão, ou seja, é como se G1 e uma parte da mídia assumisse que o Governo é culpado e isso inclui falta de investimentos em equipamentos, contratação de pessoal, passividade em relação aos atrasos e filas nos aeroportos. A outra metade, o que inclui a ênfase do Estadão, considerou as empresas aéreas, foco para TAM e GOL, como culpadas pela crise devido a prática de overbooking, ou de articulação - até com a criação do sindicato das empresas aéreas - para ter maior poder de pressão sobre o Governo sobre aumento do preço das passagens e o repasse ao consumidor.

\subsection{Cadeias de Equivalência e Diferença}

Um discurso "é representativo de uma série de demandas particulares" (FERREIRA, 2011, p.14). Neste momento de vínculo, entre diversos atores, o discurso assume sua elasticidade e evidencia que em seu interior habita uma heterogeneidade de demandas. $\mathrm{O}$ discurso amplia-se e cria uma cadeia de equivalência que alimenta o horizonte de todos aqueles que se sentem representados por alguma ação em comum (FERREIRA, 2011). Além disso, cada discurso, portanto, e cada posição no interior do discurso, constitui-se num jogo político de inclusão e exclusão de possibilidades figurados pela lógica de identificação e diferença conforme as diversas identidades e seus interesses distintos, constituintes do social.

Foi possível perceber que os blogs tratam a mídia como sensacionalista, as empresas como culpadas pela crise e os controladores de voo como injustiçados. Foi possível perceber antagonismo entre mídia privada e blogs. $\mathrm{O}$ antagonismo é entendido como a impossibilidade da constituição de um sentido objetivo, ou finalístico, a toda lógica discursiva. O antagônico é sempre um discurso exterior; é sempre, um discurso com diferente positividade. Nas palavras de Laclau, "o exterior é, portanto, um exterior radical sem medida comum com o interior" (LACLAU, 1996, p. 35). Por isso que a mídia privada como no caso do G1 tende, de 2006 a 2013, a culpar o Governo pela crise. A revista Veja tende a ter opinião sinônima. O Estadão 
se diferenciou e apresentou as empresas como culpadas. Pouco foi dado importância a questão da privatização dos aeroportos e quando isso foi tratado a mídia tratou de indicar superfaturamento no processo e que essa privatização não solucionaria a crise. As outras mídias em geral se dividiram em culpar as empresas por overbooking ou culpar o Governo por falta de investimento no setor aéreo.

Sobre essas diferenças entre as mídias privadas, Sfez (2007), invoca o fim da comunicação, pois se percebe que esta não tem mais objeto e existência, o que passa a matar o sujeito e todas as formas possíveis de comunicação. Por isso que nunca antes na história houve tantos meios de comunicação, contudo, entendemos cada vez menos. Van Dijk (2010) diz que a mídia mais desinforma do que informa, pois "podemos esperar que a mídia de massa nos informem sobre distúrbios civis, mas quem define o que é legítimo?

\section{CONSIDERAÇÕES}

$\mathrm{Na}$ TD todas as ações e objetos são significados e cada significado confere a um momento contextual e histórico específico, que é contingencial às regras vigentes e além disso, cada significado depende da ordem do discurso que constitui a sua identidade e significação, além de cada discurso ser social e político, constituído entre as práticas ou objetos que produzem posições subjetivas com que cada agente social se identifica (HOWARTH, 2000). Sobre isso Laclau e Mouffe (1985) afirmam que o Discurso equivale efetivamente à prática social. O artigo apontou, a partir da teoria de Laclau e Moufee (1985) à hegemonia das ações a partir das empresas aéreas, como a GOL e TAM, que se articularam, com a criação do sindicato para defender seus interesses contra as ações do Governo Federal.

A intenção do artigo foi compreender o discurso da mídia (desde 2006 com a chamada crise aérea) como um mecanismo capaz de alcançar a prática social como uma das peças para a construção do discurso do caos aéreo. Da pergunta central - como o discurso da mídia está significando a crise aérea? - foi possível perceber que o Governo não alcançou soluções para a crise, mesmo com a privatização dos aeroportos, feita de forma superfaturada conforme a mídia. Cadeias de equivalência foram identificadas nos discursos da revista Veja e G1, ao classificar o Governo como culpado pela crise.

Os significados para essa crise foram levantados a partir de overbooking, aeroportos com filas, atrasos e cancelamentos dos voos. Do surgimento do contexto de crise aérea para a mídia, de 2006 a 2013, o contexto representou o mesmo no que diz respeito a não solução dos problemas. Os blogs tiveram uma posição do sujeito crítica, ao julgar como injusta as 
pressões pelos quais controladores sofreram. A posição hegemônica da mídia privada permanece, muito mais desinformando do que informando, conforme Van Dijk (2010).

Do questionamento sobre: Quais são os principais sujeitos envolvidos no discurso da mídia sobre a crise? Como os principais discursos estão sendo tratados? Onde os discursos são mais intensos? Todas as demandas estão sendo tratadas imparcialmente? Foi possível perceber pelo corpus composto por 33 provedores privados e 10 blogs, o que resultou em uma análise de 113 notícias, que o objetivo da TD produziu novas interpretações de fenômenos antes não identificados por uma mídia de forma isolada. $\mathrm{O}$ artigo propiciou justamente o além do texto midiático informado, como forma de abordar de maneira crítica o não dito. Nesse contexto, o caminho teórico de Laclau e Mouffe teve natureza polissêmica dos agentes sociais e de suas lutas - o que incluiu as mídias privadas em suas disputas e os blogs como forma alternativa de divulgação. Essa direção argumentativa foi relevante para analisar os significados, a formação de cadeias de equivalência e os antagonismos do discurso da mídia.

A análise do discurso da mídia foi enriquecedor para a academia e para a sociedade, pois ultrapassou o limite do tradicional e diferentes tipos de discursos foram apresentados, nessa sociedade na qual os meios de comunicação bombardeiam com imagens, símbolos e sons (FREITAS, 1999). Perceber a crise, apenas por um desses portais, tenderia a modelar uma visão prevalecente de mundo, além de definir o que é considerado bom ou mal, moral ou imoral (KELLNER, 2001). A ilusão, da qual Freitas (1999) afirma nos manuais jornalísticos, sobre a orientação de que o jornalista ao relatar um fato, deveria ser imparcial e objetivo, é exposto como mito por Rossi (1986), pois entre o fato e a versão que é publicada, há a mediação de vários atores. Isso influencia a notícia divulgada pelo G1, assim como pelo Estadão. Sendo assim, conforme Kellner (2001), a cultura da mídia é produzida para a massa de acordo com tipos (gêneros), segundo fórmulas, códigos e normas convencionais.

Porém, conforme Freitas (2011, p. 341), "mesmo que se reconheça a quase impossibilidade de presenciarmos a democratização da mídia comercial e privada brasileira, é preciso que atores até então invisibilizados contemplem o que está sendo produzido no e pelos meios de comunicação sobre si”. Por isso, a autora diz que, mesmo que seja constatado que a decisão sobre o que é produzido pela grande mídia seja utópico, não se pode desconsiderar aspectos como: o fortalecimento da comunicação comunitária, a multiplicação de veículos de informação populares, alternativos, livres e independentes. 


\section{REFERÊNCIAS}

ARAGÃO, A. S. Interpretação consequencialista e análise econômica do Direito Público à luz dos princípios constitucionais da eficiência e da economicidade. In: RAMALHO, P. I. S.

(Org.). Regulação e agências reguladoras: Governança e análise de impacto regulatório. Brasília: ANVISA, 2009, p. 29-52.

BARBOSA, M. História cultural da imprensa: Brasil, 1900-2000. Rio de Janeiro: Mauad X, 2007.

CRUZ, V. Estado e regulação: Fundamentos teóricos. In: RAMALHO, P. I. S. (Org.). Regulação e agências reguladoras: Governança e análise de impacto regulatório. Brasília: ANVISA, 2009, p. 53-86.

DERRIDA, J. Writing and Difference, trans. Alan Bass. Chicago: University of Chicago Press, 1978.

FAIRCLOUGH, N. Discurso e mudança social. Brasília: UNB, 2008.

FERREIRA, F. Para entender a Teoria do Discurso de Ernesto Laclau. Revista Espaço Acadêmico. 2011.

FREITAS, A. F. Discurso da Mídia: um estudo de caso. Maceió: EDUFAL, 1999.

FREITAS, R. Por uma estética da periferia da periferia: Sobre modelos não-metropolitanos de Comunicação alternativa. In: Trazos de uma otra comunicacíon em America Latina. Barranquilla: Universidade del norte, 2011.

GEE, J. P. An introduction to discourse analysis. Londres: Routledge, 1999.

GLYNOS, J. HOWARTH, D. Logics of Critical Explanation. Abingdon: Routledge, 2007.

HOWARTH, David. Discourse. Open University Press, 2005.

HOWARTH, D; STAVRAKAKIS, Y. Introducing Discourse Theory and Political Analysis. In: HOWARTH, D; NORVAL, A. J.; STAVRAKAKIS, Y. Discourse Theory and Political Analysis. Manchester: Manchester University Press, 2000

JORNAL ON LINE. A História do Jornal no Brasil. Acesso:

<<http://www.jornalonline.net/2032-a-historia-do-jornal-no-brasil >> em 10 de dezembro de 2013. Texto de 26 de julho de 2008.

KELLNER, D. A cultura da Mídia - estudos culturais: identidade e política entre o moderno e o pós-moderno. Bauru: EDUSC, 2001.

LACLAU, Ernesto. Foreword. In: HOWARTH, D; NORVAL, A. J.; STAVRAKAKIS, Y. Discourse Theory and Political Analysis. Manchester: Manchester University Press, 2000

LACLAU, Ernesto. Nuevas reflexiones sobre la revolucion de nuestro tiempo. Buenos Aires: Ediciones Nueva Visón, 1996. 
LACLAU, Ernesto. On Populist Reason. London: Verso, 2005.

LACLAU, Ernesto; MOUFFE, Chantal. Hegemony and Socialist Strategy. Toward a rdicla Democratic Politics. London: Verso, 1985.

LIMA, L. A Representação das Múltiplas Dimensões Paradigmáticas no Estudo da Administração: um Ensaio sobre os Limites Contidos nas Defesas Paradigmáticas

Excludentes. RAC, Curitiba, v. 15, n. 2, art. 2, pp. 198-208, Mar./Abr. 2011

MINAYO C. Pesquisa Social-teoria, método e criatividade. $17^{\text {a }}$ ed. Rio de Janeiro: Vozes; 2000.

MCKINSEY \& COMPANY. <<www.mckinsey.com.br〉> 2010.

PAULINO, F., COELHO, J., MENDES, J. e PEDROSA, L. Projeto Dissonante: Comunicação Comunitária pela internet. In: Trazos de uma otra comunicacíon em America Latina. Barranquilla: Universidade del norte, 2011.

PERUZZO, C., TUFTE, T. e CASANOVA, J. Trazos de uma otra comunicacíon em America Latina. Barranquilla: Universidade del norte, 2011.

PINTO, Céli Regina Jardim. Notas a propósito de Ernesto Laclau. Revista de Ciências Sociales, Montevidéu, v.15, p.36-48, 1999.

ROSSI, Clóvis. O que é jornalismo. São Paulo: Brasiliense, 1986.

RUBIM, A.; AZEVEDO, F. A. Mídia e política no Brasil: textos e agenda de pesquisa. Lua Nova, São Paulo, n.43, 1998.

SALGADO, L. H. Caos aéreo e tragédia dos comuns: Falhas de mercado e de Governo. Texto para Discussão (IPEA), 1388, Fev., Brasília (DF), 2009.

SANTOS, T e SILVA, P. Comunicação e mídia na teoria crítica: algumas considerações. In: Animus - Revista Interamericana de comunicação midiática. v.11, n.22, 2012.

SFEZ, L. Crítica de la comunicación. Buenos Aires: Amorrartu, 1995

A comunicação. São Paulo: Loyola, 2007.

TORFING, J. Discourse Theory: Achievements, Arguments, and Challenges. In: Howarth, D. and Torfing, J. (Eds) Discourse Theory in Euroean Politics: Identity, Policy and

Governance. 2005.

VAN DIJK, T. Discurso e Poder. São Paulo: Contexto, 2010.

VELOSO, A. e FARIAS, H. Rádio Mulher: A comunicação feminista nas ondas do rádio no Nordeste do Brasil. IN: PERUZZO, C., TUFTE, T. e CASANOVA, J. Trazos de uma otra comunicacíon em America Latina. Barranquilla: Universidade del norte, 2011.

VIAJUS. <<www.viajus.com.br>> 2013. 
Original recebido em: 16/02/2014

Aceito para publicação em: 05/11/2015

Jouberte Maria Leandro Santos

Professora do IFPE e Doutoranda do Programa de Pós-Graduação em administração da Universidade Federal de Pernambuco (PROPAD/UFPE), recife, PE, Brasil.

Sérgio Carvalho Benício de Mello

Pós-Doutorado pela University of alberta. Professor associado do Programa de PósGraduação em administração da Universidade Federal de Pernambuco (PROPAD/UFPE) e Pesquisador nível 1D do Cnpq, recife, PE, Brasil.

Carlos Everaldo Silva da Costa

Doutorando em Administração pelo Programa de Pós-Graduação em Administração PROPAD na UFPE, Mestre em Administração pela Universidade Federal de Santa Catarina UFSC e Professor de Administração na Universidade Federal de Alagoas - UFAL. 